\title{
NOTAS
}

\section{Aspectos estructurales de Doña Bárbara}

6 6T AS cosas vuelven al lugar de donde salieron". 1 Con estas pala-

1 bras proféticas Doña Bárbara anuncia el comienzo del desenlace de la novela de Gallegos. Esta observación, enunciada misteriosamente en un momento de angustia, como intuyendo ya el desastre, sirve también para destacar uno de los aspectos tnás geniales de esta obra maestra: su redondez o simetría estructural.

El lector recordará las circunstancias en que por primera vez esta frase enigmática y vagamente amenazadora le fue "comunicada" a la mujerona. Estaba ésta en la habitación de los conjuros donde había pretendido hacer un hechizo con el cordel que medía la estatura de Santos Luzardo. Pero su hija Marisela habia entrado de repente, arrebatándole la cuerda y echando de la repisa toda la colección de imágenes y amuletos que allí estaba. Y luego había liegado Santos, llevándose a Marisela y dejando a Doña Bárbara en tal furia impotente que no pudo entrar en comunicación con "el Socio". Lo único que sacó de sus muchos esfuerzos fue la impresión de que "las cosas vuelven al lugar de donde salieron". Se ve que al formularse esta declaración, sólo podía servir de presagio al porvenir; faltaba su aplicación.

El significado del pronóstico no tarda en aclararse. Pronto se presenta ante la dueña de "El Miedo" uno de sus criados más diestros en hacer el mal, El Brujeador, a quien Doña Bárbara había dado la tarea de "trasnochar" los caballos de "Altamira": Aunque el siniestro Melquía-

1 Rómulo Gallegos, Doña Bárbara (Barcelona: Casa Editorial Araluce, 1937, p. 275). Las próximas citas de la novela, que incluiremos en el texto, se refieren a esta edición. 
des hace alarde de no dejarse engañar ni por los hombres ni por los animales, esta vez tiene que confesar que un caballo ha logrado "echarle polvo a los ojos". El Brujeador explica que la noche anterior, al trasnochar una yeguada altamireña, el padrote, llamado Cabos Negros, le llevó por la llanura abierta toda la noche en una gran galopada circular, de manera que al clarear el día se hallaban en el mismo lugar de donde habían salido. Y Doña Bárbara comprendió que así comenzaba a cumplirse la advertencia de "el Socio".

Conviene notar en este episodio de Melquíades y los caballos que aunque "las cosas vuelven al lugar de donde salieron", no se trata de una sencilla ida y vuelta en línea recta; la acción describe un círculo. En este primer cumplimiento de la advertencia, el novelista no ha querido poner en juego un ejemplo en el nivel de las emociones, la política, la economía, ni siquiera de la justicia. Mejor y más eficaz es la acción de la yeguada, en que se trata de objetos concretos en el tiempo y en el espacio. Por su misma rapidez y claridad, sirve muy bien de símbolo de ejemplos paralelos en otros niveles de la trama novelística.

De aquí en adelante el aspecto de redondez aumenta hasta convertirse en la nota dominante del desenlace. Con una precipitación casi angustiosa, todos los elementos del argumento luchan por volver a ocupar una posición anterior, formando así no un solo círculo, sino una serie de círculos concéritricos. Marisela y su padre vuelven a la inmunda choza del palmar de "La Chusmita", Lorenzo a buscar su destino y el remedio de sus desdichas en una entrega definitiva al alcohol, y Marisela a madurarse en el sufrimiento y la soledad. Entretanto, Santos Luzardo también hace su propia vuelta a las costumbres llaneras, aunque sea una medida transitoria. Obedeciendo a la "llamada de la devoradora de hombres", emprende el camino de la violencia. Pega fuego a la casa de Macanillal donde viven los Mondragones; luego toma presos a estos asesinos y los remite bajo guardia a las autoridades de Barinas, a que paguen los crímenes cometidos. Casi a continuación Santos, acompañado de Pajarote, se enfrenta con El Brujeador, y éste cae muerto de una bala disparada por el peón de Luzardo. Luego le toca a Balbino Paiba, asesino de Carmelito y robador de las plumas de garza; este ladrón perece también en el general castigo de los representantes de las fuerzas malignas, y las plumas luzarderas vuelven al poder de su verdadero dueño.

Todavía quedan por cerrar tres círculos para la feliz realización del desenlace. Estos cierres no tardan en producirse. Doña Bárbara, dándose 
por vencida en la absurda lucha por el amor de Luzardo, desentierra sus morocotas y desaparece, regresando al misterio de la selva de donde había salido. Míster Danger, viendo la imposibilidad de sacar más provecho de la situación en el Arauca, también desaparece, volviendo sin duda a su antigua vida de aventurero oportunista. $Y$ en cuanto a "El Miedo", como Marisela es heredera única de Lorenzo Barquero y de Doña Bárbara, al casarse con Santos todo vuelve a ser "Altamira": "El Miedo", el palmar y cuanto había sido motivo de litigios y disputas entre Luzardos, Barqueros y la mujerona.

Los ejemplos de redondez señalados hasta ahora en la estructura de Doña Bárbara se limitan al desenlace de la obra y tienen que ver solamente con los aspectos exteriores del argumento. Aunque de clara intención simbólica, están organizados alrededor de los elementos de la acción directamente perceptibles al lector. No menos intencionales, y acaso aún más interesantes, son las órbitas figuradas que existen en el nivel de las emociones y del carácter de los protagonistas, así como en el desenvolvimiento de las relaciones entre ellos.

Por supuesto que los dos personajes cuyo estudio resulta más atractivo en este sentido son Doña Bárbara y Santos Luzardo, aunque algunos otros llaman también la atención. No Pernalete, por ejemplo, prototipo del funcionario brutal y arrogante, personificación de la justicia pervertida, sigue ciegamente, como si estuviese tirando de una noria con los ojos tapados, un círculo de vida tan pequeño y cerrado que casi se reduce a un punto fijo. No se sabe que haya salido jamás de su distrito, ni física ni mentalmente, y deja la impresión de que ha sido siempre tal como es: un bribón, avariento y cínico, que seguirá poniendo los puntos sobre las haches. El Jefe Civil viene a ser, pues, no un individuo, sino el símbolo de un mal social.

En cambio Mujiquita salió de su pueblo natal, y cursó estudios universitarios junto con Santos Luzardo en Caracas. Fue, empero, como si no hubiese salido, porque volvió después a su aldea para seguir la misma rutina que su jefe, Ño Pernalete. Bien intencionado, pero ridículo y cobarde, carece en absoluto de redondez de espíritu y de acción. Mujiquita se destaca poco como individuo; es más bien el representante de los que consienten la criminalidad oficial, no por malicia, sino por debilidad.

Con el extraño caso de Lorenzo Barquero, historia bizarra y anómala de degeneración moral, volvemos a la estructura redonda típica de esta novela. Al regreso de Santos Luzardo a "Altamira", el último de los Bar- 
queros vive como una bestia, deshecha la voluntad, reducido a una espantosa piltrafa humana. Cuando el autor asegura que en Caracas Lorenzo "parecía destinado a un porvenir brillante" (pág. 39), hay que fijarse en la palabra parecía y tener en cuenta que las apariencias engañan. De lo que por toda la novela se puede colegir de su verdadero carácter, es evidente que nunca podía esperarle sino un trágico destino. Dejando aparte su engañosa habilidad verbal, sus finos modales, y demás consideraciones superficiales, hay que confesar que no le quedan a Lorenzo más que valores negativos.

Recordará el lector que en la disputa entre José Luzardo y su hijo Félix, cuando éste había abandonado la casa paterna para hacer causa común con los Barqueros contra su propia familia, fue precisamente Lorcnzo quien azuzó a Félix contra su padre. A pesar de su educación universitaria y todas las influencias civilizadoras de la capital, el joven Barquero no hizo esfuerzo alguno por poner fin a la enemistad entre las dos familias. Todo lo contrario: hizo lo posible por aumentar la saña y las matanzas. Compárese esta conducta con la de Santos Luzardo, cuyo primer acto después de volver al hato fue una visita a Lorenzo para restablecer la paz.

En sus relaciones con Doña Bárbara, los motivos de Barquero fueron tal vez una mezcla de atracción física, emoción de una nueva aventura $y$, sin duda, vanidad masculina en la conquista de una mujer hermosa y rebelde - todo menos amor verdadero. $Y$ al nacer Marisela, Lorenzo se mostró incapaz de la menor emoción de padre. Ni en todos los años que vivieron juntos en el palmar reveló el más leve sentido de responsabilidad por el bienestar de su hija. Rómulo Gallegos es algo inexacto, pues, al denominar "ex hombre" a Lorenzo Barquero, porque se ve que éste nunca fue un hombre en el sentido completo de la palabra, sino un ser parcial. El "porvenir brillante" que parecía prometer su primorosa juventud no era más que un espejismo; y cuando vino a patar al fin en el cieno del palmar al borde de tremedal, no hacía más que seguir la ótbita natural de su destino: el que siempre tuvo alma de lodo volvía al lodo con la totalidad de su ser.

A veces la estructura, como otros aspectos de una novela, refleja la intención docente o propagandística del autor. Doña Bárbara, cuyo subtítulo podria ser, a semejanza del Facundo de Sarmiento, "Civilización y barbarie en la República Venezolana", revela el plan de Gallegos en la disposición de las órbitas biográficas de los protagonistas. Bárbara, cuyo 
"origen se perdía en el dramático misterio de las tierras vírgenes" (pág. 31) del Orinoco, llega, tras violentas aventuras, hasta el hato de los Barqueros en el valle del Arauca. Allí se arraiga y conquista poder económico y político, asimilando al mismo tiempo algo de la tosca semicultura de esa tegión. Y alli también llega al cenit de su drama personal, para regresar luego a su obscuro punto de origen. En cambio, Santos Luzardo, oriundo del Arauca, empieza las acciones vitales de su carrera donde Bárbara termina las suyas, aunque él pasa por etapas paralelas y hasta correspondientes. Partiendo para Caracas con su madre a la edad de catorce años, a consecuencia de la trágica muerte de su padre y de su hermano, pasa en la capital un período de desánimo y tristeza. Pero, recobrándose al fin, Santos también hace conquistas en el nuevo ambiente; no son, por cierto, de cacicazgos, como las de Doña Bárbara, sino de poder intelectual y cultural. Y cuando el doctor Luzardo, ya hombre maduro, vuelve por fin al hato ancestral, está claro que ha hecho Ia conquista más importante de todas: el dominio de sí mismo. En la lucha futura se guiará con la razón y la voluntad, y no se dejará arrastrar por la pasión.

Es de notar que el punto de contacto entre las órbitas de los dos protagonistas coincide geográficamente con el lindeto entre "El Miedo" y "Altamira". En esa línea divisoria está situado el palmar de "La Chusmita", motivo de pleitos y asesinatos entre Luzardos y Barqueros, escena del primer encuentro de Santos con Marisela, y del castigo y muerte de Lorenzo. Y allí mismo también se libra el conflicto entre Santos y Doña Bárbara, o sea entre civilización y barbarie, la razón contra la pasión, o el bien contra el mal.

En el nivel psicológico, se percibe esta misma redondez estructural de los personajes principales. A pesar de la sangre mestiza de Doña Bárbara, y de las circunstancias poco favorables en que pasó sus primeros años, le cupo en suette enamorarse en la edad de su inocencia de un joven sencillo y bueno. Es decir, que le fue permitido amar al hombre antes de odiarlo. Ella perdió a Asdrúbal de una manera atroz, y el "implacable aborrecimiento al varón", que desde aquel día abrigó en el pecho, era su manera de castigar a todos los hombres por la pérdida de ese primer amor y por lo que sufrió después a manos de los piratas. Pero ya había conocido la felicidad de un afecto generoso y puro, y esto dejó en ella, no sólo "el ansia de bien", sino la posibilidad de buscar la redención y la paz por el sendero del amor. Doña Bárbara 
había de pasar por un largo y doloroso camino de odios, venganzas y crímenes antes de conocer a Santos, y ya no le era posible of recer la pureza de alma que tal hombre exigiría. Pero, aunque ella no pudo despertar en Luzardo una pasión recíproca, la misma sinceridad de este nuevo amor. le dio fuerzas para "entregar sus obras" y sacrificar su propia felicidad en favor de su hija.

Santos también parte de un amor y después vuelve a él, pero en su caso no se trata de paz y redención sino de la tenovación de un aspecto de su ser en las fuentes alegres y emocionantes de su niñez. La trama está combinada de tal manera que el redescubrimiento del cariño al Llano parece una consecuencia natural de su vueita al hato; la decisión de no vender Altamira, después del acto simbólico de sacar la lanza del muro, parece implícito en el deseo de poner fin a los antiguos rencores de familia y a los latrocinios de Doña Bárbara y Balbino Paiba. Hasta el triángulo amoroso en que viene a encontrarse Santos con Marisela y la dueña de "El Miedo" se presenta casi como una casualidad resultante de esta decisión. En realidad, la figura de Luzardo, tal como nos la pinta el autor en el momento de la llegada al hato, no corresponde al concepto popular del héroe llanero: el hombre robusto y activo, de modales rudos y toscos, y muy de "pelo en pecho". Los años pasados en la capital le han convertido en un caballero correcto y elegante, y esto, aunque lógico, pide modificación. Sin quitarle nada de sus atributos de cultura y civilización para la lucha contra la barbarie, hay que cambiar la impresión de "patiquincito presumido" (pág. 47) que le produce, por ejemplo, a Carmelito.

Gallegos logra estc efecto del modo más natural y convincente: haciendo recobrar a Santos su amor y entusiasmo por las actividades peligrosas y emocionantes de la vida llanera. Y ¿qué más a propósito que la doma de un fogoso potro-la "prueba máxima de llanería"? Es evidente que Luzardo ha empezado a ganarse la confianza de los peones cuando Carmelito confiesa, emocionado: "Me equivoqué con el hombre" (pág. 90). Y más tarde, en el rodeo, la destreza y el brío de Santos con la soga son para los llanetos la última prueba de su hombría, arrancándole a la misma Doña Bárbara la exclamación: "¡Oh, llanero bellaco que es usted!" (pág. 195) Así, el retorno de Luzardo al amor de la tierra, aunque sirve el propósito de que se le acepte y respete en el Arauca, tiene la finalidad novelística de representar en forma completa y redonda el desarrollo psicológico del protagonista. 
Una de las figuras más notables de Doña Bárbara es la del bobo, Juan Primito. Es, además, una creación completamente original. En la literatura mundial no faltan bobos, idiotas y maniáticos de muchas clases, pero no hay ninguno como el maravilloso Juan Primito. Repugnante y malicioso, es a la vez capaz de amor, ternura y celos en lo que toca a su único cariño, Marisela, la "niña de sus ojos". E1 bobo hace un papel de primera importancia en la estructura de la obra, con una función práctica en el nivel de la acción, y una finalidad simbólica en el de la psicología de la protagonista. Sin Juan Primito, faltaría un eslabón entre las órbitas de acción de "El Miedo", el palmar y "Altamira". El bobo, en su calidad de recadero de la mujerona, es el nexo entre los tres personajes, y corre sin cansancio el circuito del triángulo formado por Doña Bárbara, Marisela y Santos Luzardo. En cuanto a los "rebullones", los pájaros fantásticos que son la principal manía del lunático, Gallegos nos informa que en "El Miedo" éstos son tenidos por "una especie de materialización de los malos instintos de Doña Bárbara". (pág. 173). Lo que importa aquí es señalar el efecto artístico y el significado psicológico de esa materialización.

Las acciones que revelan una manía, como indicios de una mente enferma o débil, son, casi por definición, ilógicas e irracionales. En general, la absurda conducta de un maniático no suele reflejar más que la tormenta de las alucinaciones interiores; cuando viene a representar las intenciones de otra persona, como en el caso presente, seguramente implica algo con respecto a esas intenciones, y pone en duda la cordura de la persona que las tiene. Conviene notar también que en "El Miedo" todo el mundo está enterado de la fuente de inspiración de la manía de Juan Primito con la sola excepción de la misma Doña Bárbara. Esta circunstancia no sólo complica el asunto, sino que le presta un interés especial. Ya se sabe que una de las caracteristicas de cierta clase de demencia es la separación o partición de la personalidad en tal forma que el individuo no se da cuenta en un determinado momento de lo que hace en otro; por esto, el paciente suele ser el único que no reconoce los síntomas de su propia condición.

Lo que se colige de esto no es que el novelista haya querido atribuir a Doña Bárbara una auténtica enfermedad mental, por lo menos en un sentido médico, sino que ha logrado proyectar, en la forma de una representación dramática, un caso paralelo con el empleo de dos personajes. Su finalidad psicológica es la clara imputación de que todas 
las argucias y maquinaciones de Doña Bárbara son, como sus comunicaciones con "el Socio," tan irracionales como los rebullones de Juan Primito.

En efecto, el concepto que tenía Gallegos del estado psicológico de la mujer no distaba mucho de la enajenación mental - condición resultante, sin duda, de la combinación de fuertes pasiones y de un temperamento supersticioso. Cuando, al principio del capítulo viii, Santos acaba de recibir de Doña Bárbara la siniestra invitación para la cita de Rincón Hondo, nos informa el autor que "No dejó de ocurrírsele a Santos Luzardo que sólo en una cabeza ofuscada podía haber brotado la idea de invitarlo, de manera tan absurda, a caer en una celada..." (pág. 339). Y ¿por qué ha preferido el autor presentar a su protagonista como una mujer medio enajenada? Seguramente porque, aunque no resulta menos mala así, parece menos culpable: ya se sabe que los locos no son responsables de su condición ni de sus acciones. La maldad puede existir en cualquier parte, pero la de Doña Bárbara tiene la función novelística de representar la barbarie de la llanura venezolana. Gallegos percibió muy bien que el modo más eficaz de realizar esta identificación según las intenciones docentes de la obra sería el de hacer destacar a la protagonista como símbolo patológico de una sociedad inculta y bárbora.

Pero la función novelística de Juan Primito en sus relaciones con la mujerona no se limita a la bizarra manifestación de las intenciones de ella. Se recordará que al nacer Marisela, cuando ésta quedó rechazada por ambos padres, fue Juan Primito quien veló por la niña, le dio sustento, ropa y amor, y hasta le puso nombre, haciendo las veces de madre mucho más que las de padre. Mas no es solamente que el bobo supla el cariño y los instintos maternales de los que carece Doña Bárbara, sino que estos dos personajes son tan completamente dispares, tanto en lo físico como en lo psicológico, que se complementan en todo. A la soberbia belleza de la mujerona corresponde la fealdad repugnante de su recadero. La voluntad imperiosa e inflexible del ama encuentra su complemento perfecto en la obediencia servil e incondicional del criado. Si ella es cruel, avara y atrevida, él es tierno, generoso y cobarde. La dueña de "El Miedo" odia a los hombres al mismo tiempo que los necesita y se siente atraída por ellos; y el bobo teme a la mujeres y se imagina perseguido por algunas que "corren desnudas detrás de él, visionario, por la sabana desierta" (pág. 178), pero al mismo tiempo necesita 
obedeceder a Doña Bárbara y servir a Marisela. Y finalmente, la astucia malévola de la protagonista tiene su parte correspondiente, pero contraria, en la aparente simpleza del recadero.

Es decir, que en la estructura interior de la novela, Juan Primito sirve de espejo a Doña Bárbara. A primera vista, no parece reflejar más que las intenciones de ella en la manía de los rebullones. En realidad, lo que revela no es la imagen de Doña Bárbara tal como es, sino una figura negativa, o inversa, que representa lo que le falta a ella para ser una persona redonda y completa. De modo que estos dos personajes, siendo tan distintos y opuestos en todo, se combinan para formar, algo a la manera de Don Quijote y Sancho Panza, un complejo psicológico de elcmentos dispares y complementarios, el cual funciona y se evidencia sólo en la asociación entre los dos. Por supuesto que Doña Bárbara es el elemento dominante de esta combinación (como lo es también Don Quijote en la obra de Cervantes), no solamente por ser ella el ama, sino porque tiene un carácter más desarrollado, capaz de existir sin su recadero. En cambio, Juan Primito, fuera de la relación que tiene con la protagonista, apenas tendría papel que desempeñar en la novela. Sin embargo, es evidente que dentro del concepto de Gallegos, la figura de Juan Primito es imprescindible a la representación de la personalidad simbólica de Doña Bárbara. Como en la novela cervantina la locura idealista del hidalgo se destaca eficazmente sólo en presencia del materialismo realista del escudero, así la maldad patológica de la mujerona del Arauca se hace sentir con éxito en las manías y características del extraordinatio Juan Primito. Este paralelismo estructural entre la novela venezolana y la obra maestra española es uno de los muchos puntos que, guardando las diferencias de calidad y de tenombre las dos tienen en común. Como ya ha observado Arturo Torres-Rioseco, refiriéndose a Doña Bárbara, pero sin entrar en estos detalles: "Mientras más se asemeja una obra al Quijote, mejor novela es."2

En las últimas páginas de la obra, Doña Bárbara, vencida ya por Luzardo, va cabizbaja camino a su destino. Al pasar junto al tremedal, $y$ "no obstante el profundo ensimismamiento en que iba sumida," le llama la atención la extraña actividad de las aves que vuelan "describiendo círculos atormentados en torno a la charca y lanzando gritos de un pánico impresionante" (pág. 386). Con este presagio trágico, que rccuer-

2 Grandes novelistas de la América Hispana (Betkeley and Los Angeles: University of California Press, 1941), p. 54. 
da vivamente los rebullones de Juan Primito, refrena su caballo y presencia una escena horripilante: "Una res joven se debatía bramando al borde del tremedal, apresada por el belfo por una culebra de aguas..." (pág. 386). "Hoy come el tremedal," observa la mujerona. Y ante sus ojos comienza a ceder la víctima de la desigual contienda, se hunde en el pantano y "el agua pútrida se cerró sobre ella con un chasquido de lengua golosa" (pág. 387). El tremedal, siniestro símbolo de la ferocidad de la sabana, está al recibir una nueva víctima. Con los círculos que rizarán levemente la conmovida superficie, se cierra para siempre la vida de la cacica del Arauca.

Connecticut College

GLEN L. KOLB

New London, Connecticut 